\title{
Una antropóloga en la policía: una reflexión sobre actuación de género y relaciones de poder en el campo*
}

\author{
Mariana Sirimarco**
}

\section{Resumen}

Dentro del corpus de trabajos que reflexiona acerca de las particularidades que conlleva el hecho de ser una mujer investigando espacios habitados por hombres, es usual que las aproximaciones de género -coqueteos, avances, proposicioneshayan sido mayormente abordadas en términos de lo sentimental o lo sexual. Este trabajo busca proponer una lectura complementaria, capaz de plantear las aproximaciones de género como insumos que juegan un rol preponderante en el proceso de construcción y tensión de las identidades individuales y de las modalidades de relacionamiento en el campo.

Palabras clave: Antropóloga, Policía, Género, Poder.

* Recibido el 17 agosto 2018, aceptado el 15 julio 2020.

** Investigadora Independiente Conicet - Universidad de Buenos Aires, Buenos Aires, Argentina. maikenas@yahoo.com.ar / ORCID: 0000-0003-3074-1435. 
A Woman Anthropologist in The Police:

A Reflection about Gender and Power Relations in The Field

\begin{abstract}
Among the literature reflecting on the particularities of being a woman researching social spaces inhabited by men, it is common that gender approaches like flirting or making propositions are mostly addressed in sexual or romantic terms. This study seeks to offer a complementary reading, capable of considering gender approaches as inputs that play a fundamental role in the process of constructing and challenging individual identities and social relations in fieldwork.
\end{abstract}

Keywords: Woman Anthropologist, Police, Gender, Power. 
Esa mañana, como tantas otras antes, estaba presenciando la clase de Derecho de Familia y Minoridad. Hacía un año largo que venía acompañando a la docente -Marta, ${ }^{1}$ profesora universitaria y abogada- en sus clases en esa escuela policial. Cada tres meses cambiaba el grupo; éste ya estaba llegando al final de su cursada. Podía decirse, por eso, que más o menos nos conocíamos. Ya habían pasado los temores iniciales y las tensiones que se derivan de todo nuevo encuentro. Ellos ya no creían, como al principio, que yo fuera una enviada del Ministerio que estuviera espiándolos. ${ }^{2}$ A lo largo de esos tres meses, a razón de un día por semana, la rutina se había encargado de volvernos cotidianos. El carácter de Marta, de generar un ambiente cordial pero cuidadoso, donde se guardaban las formas no por temor sino por respeto.

Ahora me doy cuenta de que debía ser la última clase, porque terminaba la hora y aun la veo a Marta diciéndoles, a los alumnos, que podían llamarla por teléfono, a partir de la semana siguiente, para pedirle las notas del final de la cursada. Los recuerdo a todos anotando prolijamente el número de teléfono que Marta les dictaba y a uno alzando simultáneamente la voz y la mano para preguntar algo que sólo el clima del día final, en ese aula y en esa materia, podía haber habilitado: "¿a la oyente también se la puede llamar?". "No, por el parcial no se me puede llamar", me veo contestando, en una escena que todavía pasa en loop ante mis ojos, queriendo seguramente diferenciar que yo era antropóloga y no oyente y menos profesora, pero quedando en cambio, con un movimiento torpe de principiante, en completo orsay.

"No, claro -el tono era del que recibe el gol servido-, por el parcial no".

\footnotetext{
${ }^{1}$ Éste, como todos los que aparecen a lo largo del texto, es un nombre ficticio.

${ }^{2}$ Volveré sobre esto a continuación.
} 
Durante los dos años que duró mi trabajo de campo en esa escuela, fui -o tengo la ilusión de haber sido-, muchas cosas. Espía de Ministerio, en los primeros momentos del encuentro. Antropóloga en ejercicio, inmediatamente a continuación, cuando la primera identidad se desmoronaba a costa de conocernos. Después, como complemento o como chanza, oyente, asistente de sus profesores, mudita, ${ }^{3}$ o -ya en tonos más realistas- becaria del Conicet o docente en la Universidad de Buenos Aires. Pero antes que nada, y sobre todo -como la escena anterior intenta dejar en claro-, yo era mujer y era joven en un ámbito mayormente habitado por hombres co-generacionales. ${ }^{4}$ El registro imbricado de sexo, género y edad era, a pesar de mis esfuerzos por restarle trascendencia, una variable de peso en mi discurrir por el campo. ${ }^{5}$ Ya podía yo desesperarme por ser vista como antropóloga, o fastidiarme al ser tomada por espía. Ninguno de esos dos roles obstaba para que yo siguiera siendo, sin embargo, siempre -y en primera instancia- una mujer.

Lo que se sigue de esta afirmación es a todas luces evidente: que a despecho de mi voluntad y hasta de mi registro consciente, el género fue, durante mi trabajo de campo en las escuelas policiales, uno de los clivajes que más fuertemente reguló el cariz de los tratos y las interacciones. Si así sucedió fue porque esta

${ }^{3}$ Porque -me explicó luego un grupo de alumnos al revelarme mi apodo- lo único que veían que yo hacía era anotar todo y nunca hablar. "Vos siempre apabullando tanto, con ese timbre de voz", era de hecho algo que, con variantes, solían decirme. Volveré sobre esto en el último apartado.

${ }^{4}$ Como se aclarará a continuación, los alumnos eran policías de unos siete años de antigüedad en su profesion. Es decir que rondaban, aproximadamente, los veintiseis años

${ }^{5}$ Hablar de "campo" implica, por supuesto, hablar de una situación relacional. Más o menos pasible de ser delimitado territorialmente, no es un lugar empírico sino una modalidad de contacto. En todo caso, si existe un territorio hacia el que el/la antropólogo/a "vaya" en la situación etnográfica, éste no es más que un espacio dependiente de las interrelaciones entre sujetos. El campo no es la Escuela. Es, en todo caso, esa trama más o menos inasible conformada por las relaciones de sociabilidad que armamos quienes nos encontramos en ella (Eilbaum y Sirimarco, 2006; Sirimarco, 2010). 
estructura no sólo alude a una forma de diferenciación categórica que mantiene relaciones con la referencia sexual, sino que se transforma en el insumo mismo que moldea las formas que asumen las distintas interacciones sociales (Piscitelli, 1995). Atendiendo a la dimensión performática de lo genérico es que hablo entonces de actuaciones o aproximaciones de género, en tanto aquellos scripts que permiten moverse por el entramado social; es decir, en tanto aquellas estructuras que -a partir de los imperativos que la constituyen- permiten poner en escena un determinado texto social (Butler, 1999).

Lo que intento decir es que mi "identidad" de género, por llamarla rápidamente de algún modo, se transformó entonces, desde el primer momento, en un componente esencial en las relaciones que establecí en el campo. Un componente obvio, si se quiere. Y por obvio, invisibilizado. Uno que parecía no estar operando al establecer contactos, charlas, conversaciones más formales o entrevistas, pero que se encontraba sin embargo en la raíz misma de todas estas interacciones:

Aula 1, última clase de Deontología. Ya al final de la hora, antes de los abrazos de despedida y la foto para el recuerdo, empiezan a circular el mate y las facturas. Marcos abandona su usual asiento en el fondo y viene a sentarse justo enfrente mío. Habla con los otros chicos, se hace el langa. De pronto, no sé cómo, queda encargado del mate. Se acerca el profesor y le pregunta si está cebando dulce o amargo. Que amargo, responde, mirándome de lleno, "que para dulce está ella" (Registro de campo).

Son numerosas las reflexiones acerca de las particularidades que conlleva el hecho de ser una mujer investigando espacios habitados por hombres, y que han abordado las zozobras del campo a partir de la indagación de construcciones (y preocupaciones) genéricas tales como las concernientes a la seguridad, la protección y/o la vulnerabilidad de lo femenino (Golde, 1986; Bell et al., 1993; Kulick y Wilson, 1995; Dubisch, 1995; Wolf, 1996; Williams, 1996; Flinn, 1998; Cupples, 2002; Gill y MacLean, 
2002; Markowitz, 2003; Huggins y Glebbeek, 2003; Moreira, 2004; Alcázar-Campos, 2014). ${ }^{6}$ Dentro de este corpus citado, es usual que estas aproximaciones de género en el campo hayan sido mayormente abordadas, también, en los términos más o menos literales de lo sentimental o lo erótico. Es decir, como intentos reales de contacto sexual y/o romántico.

$Y$ aquí es donde se asienta el interés de este trabajo: en proponer una lectura de estas aproximaciones de género que no se estanque en la figura de la mujer antropóloga (en campos masculinos) como signo de deseabilidad sexual. Si acordamos en que la identidad de género no es nunca una identidad estática, ni es tampoco una identidad en cuyo proceso fluctuante se tenga siempre el control (Back, 1993), resulta evidente plantear al posicionamiento de género como un proceso mediante el cual disputar roles y competencias. Esto es, como un insumo que juega un rol preponderante en el proceso de construcción y tensión de las identidades individuales $\mathrm{y}$ de las modalidades de relacionamiento en el campo.

6 Es usual que las mujeres que investigamos fuerzas de seguridad seamos sometidas, de modo recurrente, a una pregunta a mitad de camino entre la curiosidad, el asombro y cierta dosis de cuestionamiento: ¿cómo hacemos para hacer investigación en estos ámbitos? De más está decir que los hombres que investigan los mismos espacios no oyen tan asiduamente tales interrogantes, lo que no hace sino consolidar un problema potencial: el de desplazar el foco del interrogante desde el cómo de esos espacios hacia el por qué de la mujer. El asombro que suscita el trabajo de campo en esas instituciones parece amplificarse por el hecho de haberlos elegido no siendo hombre. Desde ya, no se trata de evitar las preguntas problematizadoras, sino de evitar las preguntas asombradas. Es decir, de evitar reproducir, mediante la exotización, los encasillamientos binarios y los prejuicios de género, al estimar que hay ámbitos más o menos convenientes para uno u otro sexo, y prácticas y sentidos -la fuerza, la violencia, las armas- de los que las mujeres debiéramos resguardarnos, so riesgo de algún peligro. La apuesta de este trabajo pasa entonces por indagar los tonos específicos con que se tiñe el cruce especial entre estas variables -antropóloga y ámbitos masculinos- pero nunca por exotizar el hecho mismo del cruce en sí. Se trata también de cuestionar todo lo que la imagen de la antropóloga (vulnerable) en un campo masculino puede tener de sesgada, y de abogar por reflexiones más complejas del lugar de la mujer y de lo femenino en ámbitos de investigación como los analizados. 
A la luz de este entendimiento, este trabajo no es sino el complemento necesario de uno anterior. Me refiero a uno que escribí hace ya algunos años, donde abordaba esos constantes rumores de espionaje que mencionaba anteriormente y que habían permeado, de modo casi constante, los primeros tiempos en el campo (Sirimarco, 2012). Déjenme recapitular brevemente el argumento. Para los alumnos, oficiales ya en servicio que se encontraban haciendo un curso para ascender en la jerarquía, mis explicaciones del oficio antropológico no hacían sino caer en saco roto. Para ellos, la presencia de una mujer joven dentro de esa institución poco se explicaba por la apelación a tesis doctorales y disciplinas sociales exóticas. Mucho más factible, en su universo, era que yo fuera personal del Ministerio de Seguridad (la otrora antigua Jefatura de Policía) enviada para espiar sobre ellos y sus opiniones.

De algún modo era entendible: la figura del "espía" cuadraba mucho mejor en un ámbito habituado a la pesquisa y especializado en la inquisición como herramienta de trabajo (a la vez que sensibilizado en el temor de la filtración de algún dato o secreto). Pero no hablaba de esto en aquel escrito, sino de la figura del antropólogo sospechado no sólo como referente de los primeros tiempos en el campo, sino como modo de enfrentar la presencia del etnógrafo y de disputar los roles en el proceso de investigación.

Me interesaba argumentar, en aquel trabajo, que la resistencia del otro, lejos de ser entendida como un capricho, debía percibirse como un ejercicio de co-construcción del campo. Pues esa intrincada construcción de sospecha, espionaje, recelo $e$ intransigencia con que los sujetos enfrentan al/la etnógrafo/a y su trabajo se complejiza al ser leída como una instancia a partir de la cual socavar la supuesta autoridad del/la etnógrafo/ $\mathrm{a}^{7}$ y negociar

\footnotetext{
${ }^{7}$ Hablar de autoridad etnográfica es aludir a múltiples niveles de análisis, desde las condiciones políticas y epistemológicas implicadas en la producción de la investigación hasta aquellas referidas a la producción de textos. En este trabajo, sin embargo, esta categoría estará recortada en relación al proceso mismo del trabajo de campo -a las demandas, constreñimientos, acuerdos, negociaciones y
} 
los límites de la investigación. Es decir, al ser leída como un recordatorio de que ni el curso que sigue el análisis es monopolio exclusivo del/a etnógrafo/a, ni este rol de investigación resulta una instancia sólida e impermeable, bajo el puro control del/la cientista social.

Así, la figura del antropólogo sospechado ser convirtió, para mí, en el modo de abordar la clave de lectura que se abre cuando cuando entendemos que todos/as -antropólogos/as incluidosestamos (o somos) políticamente situados. Que todos/as somos continuamente explicados/as y posicionados/as por los otros: continuamente tanteados/as, contrastados/as y entendidos/as. Cuando entendemos que la interacción con el otro implica, necesariamente, que ese rol de investigador/a en el que uno/a se acomoda pueda ser desdibujado, disputado, confrontado y hasta utilizado para provecho de esos otros (Daich y Sirimarco, 2009; Sirimarco, 2010, 2012).

El escrito al que refiero abordaba sí esa figura, pero dejaba fuera del análisis un posicionamiento paralelo a éste, y tan importante en mi experiencia de campo como el anterior. Un posicionamiento que salía a relucir discursivamente cuando aquel del espionaje caía en desuso, pero que por supuesto lo precedía. Me refiero a aquel que las palabras de Marcos y el otro alumno dejan entrever: el posicionamiento de género.

¿Qué significaba, en mi trabajo de campo, el ser continuamente percibida y posicionada según estos y otros parámetros genéricos? Esta pregunta, válida para cualquier mujer en cualquier campo, adquiere sin embargo otra intensidad cuando se trata, como en mi caso, del trabajo de campo de una mujer en el ámbito policial. Es decir, en un ámbito no sólo compuesto mayormente por hombres, sino en uno que comercia, profesional y tan fuertemente, con un ejercicio particular de la masculinidad. ${ }^{8}$

ansiedades con que todos los sujetos que lo habitamos lo vamos coconstruyendo- y en relación a la percepción del/a etnógrafo/a en tanto sujeto de poder. Se volverá sobre ello más adelante.

${ }^{8}$ La masculinidad no debe ser entendida, linealmente, como el comportamiento de los hombres, ya que la actuación de lo genérico no puede equipararse (ni 
¿Qué roles y habilidades se disputaban cuando los alumnospolicías me interpelaban según estas actuaciones generizadas? ¿Cómo se vinculaban, estas interpelaciones genéricas, con las particularidades de mi aceptación y permanencia en este ámbito? En tanto el número de investigadoras mujeres en los campos de la seguridad -tanto a nivel nacional como regional- parece ser más que importante, esta interrogación no sólo es interesante sino necesaria de inspeccionar más de cerca.

Este trabajo busca entonces detenerse en estos interrogantes y estas experiencias en el terreno. Si los primeros tiempos en la Escuela estuvieron surcados, para mí, por acusaciones de espionaje, una vez abandonados estos rumores el componente genérico no tardó en afianzarse en la mayoría de las interacciones. Así, si bien la sospecha fue una de las claves que guió buena parte de las aproximaciones iniciales, la interpelación de género fue igualmente importante y mucho más duradera. ¿Qué suman, estos datos de género, a la reflexión de la figura del/la etnógrafo/a como una empresa en colaboración? ${ }^{9}$ Prestarle atención a estos datos en este texto no es sino un modo de hacerle justicia a las argumentaciones de aquel otro texto anterior, al complejizarlo y completarlo con una mirada más abarcadora.

Pero es también, y tal vez más, un modo de visibilizar una cuestión que suele quedar por fuera de los planteos de los textos que escribimos. Aunque la literatura al respecto no es poca, sigue

confundirse) con lo anatómico. Si la utilizo para referir a la Escuela no es porque esté aludiendo a un espacio habitado mayormente por hombres, como ya explicaré, sino porque entiendo que el sujeto policial, en tanto metáfora que liga los cuerpos individuales con el cuerpo institucional, es eminentemente masculino, independientemente de que encarne en anatomías de hombres o de mujeres. Para una profundización al respecto, ver Sirimarco 2009.

${ }^{9}$ Una aclaración necesaria: hablar de la co-construcción del campo implica aludir a que el proceso de investigación, así como el rol del/a investigador/a, no son construcciones en cuya manufactura intervenga sola y exclusivamente el/la cientista social. Sin desconocer la amplia producción académica posmoderna, no es objetivo de este trabajo referir a los aportes hechos, desde este campo, a la cuestión de la polivocalidad de la autoría etnográfica y a la co-construcción del texto etnográfico (Marcus y Fischer, 1986; Clifford y Marcus, 1986). 
siendo más o menos habitual que el campo aparezca, en las etnografías, como un espacio sexual y genéricamente lavado, y que estas formas de la identidad del/a investigador/a se ofrezcan siempre, en ellas, como un subtexto sistemáticamente borrado.

Estamos habituados a repetir que, al hacer trabajo de campo, los/as etnógrafos/as nos usamos a nosotros/as mismos/as como la principal herramienta de análisis (Gill y MacLean, 2002). Pero al decir esto pareciera que pensamos, mayormente, en nuestro costado intelectual, pues a partir de él desgajamos entonces una lista de atributos "serios" y "legítimos" para la reflexión de quiénes somos y de cómo eso repercute en el campo. Pero otros atributos, los afectivos y genéricos, por ejemplo, muchas veces caen del lado de lo olvidable, quizás por algún prurito victoriano que nos persigue desde los orígenes mismos de la disciplina. ${ }^{10}$

Este trabajo busca así pensar estos ejes a partir de una experiencia concreta: la de mi trabajo de campo en la escuela mencionada -Escuela Superior de Policía "Comisario Mayor Emilio García García" de la Policía de la Provincia de Buenos Aires (PPBA)- a comienzos de la década del 2000. ${ }^{11} \mathrm{Al}$ hacerlo, su objetivo es eminentemente epistemológico, pues apuesta a consolidar el entendimiento de las experiencias de género en el campo más allá de simples recorridos personales sin significación ulterior, al conceptualizarlas no ya como anécdotas por fuera de los datos, sino como herramientas mismas que habilitan la construcción conjunta -y no siempre armónica- del campo.

\footnotetext{
${ }^{10}$ Basta recordar, si no el escândalo que produjo la publicación de los diarios de campo de Malinowski, cruzados como estaban de comentarios de índole sexual. Para una reflexión acerca de este rechazo a la experiencia sexual del/a investigador/a, ver Kulick y Willson 1995, Langarita Adiego 2017.

${ }^{11}$ Esta Escuela era, hasta el año 2005, la institución encargada de dictar aquellos cursos de capacitación que debía cumplir el cuadro de oficiales como condición previa y obligatoria para el ascenso a ciertos grados de la jerarquía. Durante mis dos años de trabajo de campo seguí una buena cantidad de los cursos que cumplían los subinspectores para devenir inspectores. En el año 2005 la Escuela Superior fue subsumida en sus funciones por el Centro de Altos Estudios en Especialidades Policiales.
} 
Hacer trabajo de campo en escuelas policiales significó, para mí, transitar espacios, como dije, mayormente habitados por hombres. Las policías argentinas son instituciones que sólo recientemente -si tenemos en cuenta su larga trayectoria históricase han abierto al ingreso de mujeres. ${ }^{12} \mathrm{Si}$ bien éstas han ido aumentando en número y en derechos con el correr de los años, la proporción de hombres dentro de estas fuerzas es todavía ampliamente mayoritaria. A comienzos del 2000, cuando realizaba mi investigación, esta proporción era levemente más pronunciada: en un aula promedio de veinticinco personas, las mujeres no pasaban de ser unas cuatro. ${ }^{13}$

En ese contexto, a nadie le extrañaría que mis charlas, formales e informales, dentro y fuera de la Escuela, así como mis entrevistas, hubiesen implicado mayormente a alumnos hombres. Pero la realidad es todavía más interesante: no recuerdo situaciones de charlas con mujeres solas (sí con grupos de alumnos que las incluían) por fuera de las conversaciones que pudieran suscitarse dentro de una clase o de los comentarios rápidos que nacían de un cruce en el baño o en los pasillos. Y revisando los archivos de esa época, confirmo otro dato: no hice, con alumnas mujeres, ninguna entrevista. Nunca, en los dos años que duró mi trabajo de campo. Que esto fuera posible -que yo no lo haya intentado, que ellas no hayan accedido- sólo refuerza el hilo argumentativo por el que transita este trabajo: la importancia de las relaciones y las actuaciones de género en el discurrir del proceso de investigación.

\footnotetext{
12 Las mujeres ingresan a la PPBA en 1947, conformando el primer cuerpo de policías mujeres en Argentina y en toda América del Sur (Calandrón y Galeano, 2013). La institución remonta sus orígenes a las postrimerías del 1500, con los primeros alcaldes ordinarios (Rodriguez y Zappietro, 1999). Para mayores datos contextuales acerca de ésta y otras cuestiones -organización, ingreso y jerarquías dentro de la institución- ver Sirimarco 2009.

${ }^{13}$ Tal vez la proporción de mujeres sea mayor en el cuadro de suboficiales.
} 
En lo que a mi experiencia respecta, eran los hombres los que se acercaban, con comentarios banales o bromas, a romper el hielo en las primeras clases en las que yo participaba (o a acusarme de espía de Ministerio). Eran los hombres los que me incluían, de modo galante, en sus observaciones en el aula. O los que se candidateaban -algunos indolentes, otros más dispuestoscuando buscaba gente para entrevistar. $\mathrm{O}$ aún los que me invitaban, en nombre de todo el grupo, a sus asados o reuniones de fin de la cursada.

No estoy subrayando con esto un interés romántico, sino una modalidad de relacionamiento que involucraba a los hombres por sobre las mujeres (y a un puñado de éstos por sobre la mayoría). ${ }^{14}$ En la dinámica del aula o en los pasillos, eran ellos los que me preguntaban cómo estaba, por qué había faltado la clase anterior, qué pensaba de esto o de aquello, cuándo iba finalmente a entrevistarlos. Si el profesor amenazaba con hacerlos volver a rendir en Diciembre, eran los que indefectiblemente contestaban: "claro, venimos, pero si Mariana viene también". O los que aprovechaban cada situación, aún desde el minuto cero, para lanzar insinuaciones galantes pero comedidas:

Aula 7, primera clase de Psicología que presencio. La conversación se pone intensa; los argumentos a favor y en contra de lo que explica la profesora van y vienen. Yo observo todo callada, al costado del aula, tomando nota. De repente uno del fondo me mira y me suelta:

-¿Habla?

Ensayo mirada fulminante y sonrisita corta:

-No.

La profesora se da cuenta de que no me había presentado, así que repara el olvido: que era antropóloga, que estaba haciendo un trabajo de campo para mi tesis de Doctorado sobre la policía, que eso implicaba ir al terreno y realizar observaciones.

${ }^{14} \mathrm{Si}$ esta afirmacion se circunscribe a lo heterosexual es porque refleja solamente mis experiencias puntuales en el campo. 
-¿Y qué necesitás de nosotros?, pregunta enseguida uno gordito, sentado cerca mío.

Otro de más lejos arriesga también rápido, en tono de levante:

$-¿$ ¿Custodia?

(Registro de campo)

Estos eventos que narro no eran, desde ya, como dije, formas concretas de cortejo romántico. Eran simples cumplidos o, si se quiere, hasta normas de cortesía revestidas de comentarios galantes. Pero no dejaban de ser, por ello, insumos de género que se activaban para delinear y reafirmar roles sociales. $\mathrm{Si}$ atendemos al género como algo que se hace antes que algo que se es (Stolcke, 2004), el guión social de la masculinidad hegemónica ${ }^{15}$ me convertía, ante los ojos de esos hombres, en un sujeto apto para tales muestras de atención considerada. En las intersecciones políticas y culturales en las que el género es producido y montado, la mirada de esos hombres leía elementos -sexo, edad, clase- que habilitaban el coqueteo (Butler, 1997). En tanto sujetos inmersos en un entorno estructurado por la diferencia sexual, esa mirada me percibía como mujer $y$, por ello, como destinataria de ciertas prácticas y ciertos discursos:

Voy llegando tarde a la Escuela. En la esquina me cruzo con el bedel ${ }^{16}$ del Aula 7 y uno de sus compañeros, Sebastián. Cruzamos miradas de reconocimiento, a la pasada. Me increpan:

Sebastián (apurado): ¿Ya cerró el negocio?

Me lo quedo mirando, desconcertada.

Bedel (le pega un codazo): iPero no, bestia, si ella es la de [las observaciones en la clase de] Relaciones con la Comunidad!

15 Se trata, desde ya, de una forma puntual de ejercicio de la masculinidad, asociada a prácticas y sentidos patriarcales y heteronormativos. De ahora en más, al hablar de masculinidad estaré haciendo referencia a esta modalidad en particular.

16 Nombre que recibe el alumno encargado del aula. 
Sebastián (vuelve a mirarme): Ah, sí. Te había confundido con la chica del puesto de café...Es que son muy parecidas...

Bedel: iSi la otra es rubia!

Sebastián: No, bueno, por lo lindas y simpáticas...

Bedel (riéndose): Bueh, pedile el teléfono también ...

Sebastián (fingiendo puchero): No, si ya se lo pedí y no me lo dio.

Bedel: Bueno, basta, que la vas a hacer poner colorada.

Sebastián (mirándome mientras me le rio en la cara): No, iqué se va a poner!

(Registro de campo)

La literatura al respecto es tan copiosa como conocida: la estructura de género brinda no sólo el imaginario de lo que significa ser hombre o ser mujer, sino también, y sobre todo, el conjunto de representaciones, prácticas y prescripciones sociales que señalan lo que es "propio" de los hombres -lo masculino- y lo que es "propio" de las mujeres -lo femenino (Strathern, 1988; Piscitelli, 1995; Lamas, 2000). Y en este mandato de masculinidad que pululaba en el campo -al menos entre los alumnos que se me acercaban-, lo propio de los hombres era, como los anteriores extractos de campo ilustran, la galantería y el piropo como modo de actuar las situaciones de diferencia sexual.

Si aquella mañana en la esquina de la Escuela merecí el piropo de linda y simpática -así como el pedido soterrado de número de teléfono- era porque lo propio de ese ejercicio concreto de la masculinidad es el ser discursivamente activo, tanto en el plano sexual como en otros órdenes de la vida (Badinter, 1993; Bonaparte, 1997; Bourdieu, 2000; Burin y Meler, 2000; Gutmann, 2003; Segato, 2003; Sirimarco, 2009). Quiero decir: avanzar con galanterías y coqueteos como forma de posicionarse y de posicionar al otro.

Pero el interés de este trabajo no es adentrarse en análisis sesudos respecto de las particularidades y alcances de los discursos de la masculinidad hegemónica, sino dejar asentadas rápidamente estas cuestiones para concentrarse en lo que sí interesa discutir 
aquí: la significación de estos relacionamientos de género en el discurrir de mi trabajo de campo en el ámbito policial. En tal sentido, el objetivo no pasa por presentar una perspectiva que detenga la mirada en las cuestiones de género per se, sino de vislumbrar cómo, a través de estos índices genéricos, se fue delineando - $y$ avalando- una cierta forma de ser y actuar dentro de esa específica escuela policial.

¿De qué nos hablan, entonces, estos modos genéricos de relacionarse? Nos hablan, en principio, de un modo de actuación que encuentra, en la agencia policial, un nicho fecundo. De hecho, la figura del "policía mujeriego" es una estampa de la cual muchos se vanaglorian. Lo sean realmente o no, lo cierto es que el tópico funciona tejiendo una vinculación estrecha entre lo policial y cierto ejercicio exacerbado de lo masculino. No por nada un viejo chiste que circula al interior de la fuerza se ufana de que es del policía el único velorio con dos viudas.

Uno de los alumnos de la Escuela me lo explicaba una vez en estos términos: "el policía es muy mujeriego porque están rotos los lazos con su familia. Trabaja todo el día afuera, hace turnos de varios días, a la mujer y los hijos casi no los ve. Entonces, cinco minutos con una amante, sí se puede. A tu mujer no te la podés coger, tenés que amarla". Algunos años después de ese trabajo de campo, un policía más curtido me lo contaba de otro modo: "es que el vigilante $e^{17}$ es cararrota como yo, cara de piedra. Total el "no" ya lo tengo seguro. Aparte, como decimos los vigilantes, de veinte [mujeres] que te chamuyás en la calle, una te va a dar cabida. Todos los vigilantes tenemos dos o tres mujeres".

Chamuyar es signo de masculinidad. Era lo que hacían conmigo, porque era lo que hacían entre ellos. Quiero decir: ya ha sido suficientemente señalado que la sexualidad en el espacio policial se vuelve un insumo estratégico para la regulación de las relaciones profesionales. Desarrollar estas relaciones dentro de las dependencias policiales no sólo es bien visto: es hasta una

\footnotetext{
${ }^{17}$ Modo de aludir al policía pertenenciente al cuadro de suboficiales. Es decir, al personal subalterno.
} 
habilidad necesaria que hombres y mujeres despliegan para manejarse en el trabajo, pues el ejercicio de la sexualidad, así practicado, se transforma en una herramienta apta para la negociación y la construcción de relaciones de poder desde donde obtener prebendas (Calandrón, 2014; Sirimarco, 2017). En este contexto, el chamuyo constante del "policía mujeriego" no es sólo la actuación intensa de un guión general de masculinidad, sino, más aún, el ejercicio específico de un modo de sociabilidad policial.

$Y$ es en este punto que se abren consideraciones de mayor peso. Pues los relacionamientos de género en el campo, tal como fueron por mí experimentados, no sólo nos describen escenarios de actuación de lo masculino. Nos enfrentan, por el contrario, al ejercicio de cierto registro de masculinidad como modo de instauración de relaciones de control. Pues analizar el género en su dimensión performática implica entender que su actuación es incapaz de resolverse, de modo único, y como adelantaba al comienzo de este trabajo, en términos sentimentales o románticos. Interpretar de este modo las situaciones narradas significaría proponer una comprensión ingenua y restringida de la potencialidad de lo genérico, olvidando que éste es una forma fundamental de significar poder (Scott, 1996, 2008). En mi estadía en la Escuela Superior, galanterías y piropos no eran sino el modo de hacer uso de la estructura de género -y del ordenamiento jerárquico que la subyace- para experimentar y negociar las relaciones de poder en el campo.

No por nada se ha abundantemente señalado que masculinidad-hegemónica y poder se vuelven términos intercambiables, en tanto ésta deviene un lenguaje de conquista y preservación activa de un valor. En este registro de masculinidad, que coincide grandemente con aquella alentada desde el relato policial, las actitudes resaltadas son las asociadas a lo dominante, a lo resistente, tanto como al ejercicio de lo coactivo y lo violento (Badinter, 1993; Bonaparte, 1997; Bourdieu, 2000; Burin y Meler, 2000; Gutmann, 2003; Segato, 2003; Sirimarco, 2009; Daich y Sirimarco, 2014). 
Así conceptualizado, el ejercicio de la masculinidad se despliega como un mecanismo sumamente ventajoso para establecer y remarcar posicionamientos jerárquicos, en tanto las relaciones de género -signadas por el status y la polaridadexpresan siempre una demarcación de valores diferenciales. Así, haber sido sexual y genéricamente posicionada -haber sido piropeada, coqueteada, chamuyada- implicó para mí haber sido ubicada, en el campo, en una situación concreta ( $y$ presumiblemente supeditada).

Haber sido percibida en esos términos se volvió, así, un modo evanescente pero sostenido de disputar mi papel de observadora. Haber sido recurrentemente apelada en tanto mujer joven y "abordable", y haber sido periódicamente devuelta a ese rol, se transformó en una forma hábil de hacer frente a mi presencia en tanto antropóloga investigándolos. Los piropos, los coqueteos, los avances, se volvieron entonces una forma de restaurar la paridad que mi supuesto lugar de indagadora parecía desafiar, y de equilibrar así nuestros espacios de "poder". A mis expectativas modestas de ser percibida en tanto antropóloga (o no-espía), ellos no hacían sino oponerle sus propias (y genéricas) expectativas.

Recuerdo un momento puntual del campo en que esta incomodidad que yo parecía a veces generarles se tornó más palpable:

Recreo. Vuelvo al Aula 2, a pedir voluntarios para una entrevista. Bruno se ofrece, entre amable y canchero. No faltan las risas y los chistes infantiles de los compañeros. Que si gusta de mí. Que si entre nosotros pasa algo. No los secunda, pero es obvio que los disfruta. Llueven las recomendaciones para él: al menos, que yo le pague el almuerzo. En medio de las bromas, le pregunto si no tiene problemas en que la charla sea con grabador. Me contesta algo, también en broma, que suscita la carcajada general: "¿y yo puedo ir con una pistola con silenciador?". (Registro de campo) 
La imagen, creo, no puede ser más clara. A mi pedido de entrevista, Bruno y sus compañeros contestan con sus chanzas y sus roles de género. Ante la reiteración de mis competencias, Bruno responde con las suyas. Lo amenazante se emparda con lo amenazante. ${ }^{18}$ Por supuesto, se trataba de una broma, y nunca fue entendida por mí de ningún otro modo. Pero la jocosidad no invalidaba, de todas maneras, la presencia de cierto recelo.

Lo aquí narrado debe sumarse a los extractos de campo anteriores, pues nos permite comprender que las chicanas -las de género y las otras- estaban ahí para recordarme quiénes éramos, finalmente, ellos y yo, y dónde estábamos. Si yo era antropóloga, para ellos yo era mujer. Si yo era inquisidora, ellos eran policías. No se trataba obviamente de una amenaza, sino de un movimiento que buscaba resolver, mediante el humor o el coqueteo, el desafío de la autoridad de los otros (Fonseca, 2000; Sirimarco, 2012).

Ningún policía verá, en esta situaciones, más que un chiste. Pero en esto radica justamente lo interesante: en las percepciones que, a través de ciertos mecanismos, se dejan entrever, donde la posibilidad de ser abordado (con preguntas) se resuelve siendo el que aborda (con coqueteo), y la tenencia de un grabador que pudiese comprometer al policía se contrarresta con la pistola con silenciador que pudiera protegerlo. Ante una antropóloga y un grabador percibidos como amenazantes, el coqueteo y el arma se transforman así en recursos que garantizan un ejercicio activo del control, y que nos devuelven al paradigma de la masculinidad, la fuerza y la violencia que invisten al policía como sujeto de poder (Sirimarco, 2009, 2012).

En la Escuela, los alumnos encontraban este "poder" en el ejercicio discursivo de la galantería; es decir, en la actuación de cierta masculinidad conquistadora. Así, estos relacionamientos de género para nada buscaban el involucramiento sexual o amoroso -

${ }^{18}$ Lo amenzante, acá, es la confusión de la antropología con el oficio periodístico, y el riesgo de que lo dicho por ellos ante mi grabador pudiera luego aparecer publicado en cualquier diario. El temor no es sólo a la divulgación del nombre y apellido, sino a las consecuencias institucionales de expresar la opinión. 
y eso era absolutamente claro para todos/as-, sino, creo yo, la instauración de una estructura cotidiana de paridades, a partir de la cual re-posicionarse activamente en un vínculo percibido como tensionante. El ejercicio simbólico del género parecía surgir entonces como una suerte de delicado mecanismo de contrapeso, buscando instaurar aproximaciones que ayudaran a desafiar - $\mathrm{O}$ a mitigar- mi autoridad etnográfica en el campo. ${ }^{19}$

\section{III}

Si el apartado anterior se ha ocupado de las actuaciones de género a partir del piropo y el coqueteo, esto no significa que no hubiera, en la Escuela, otros modos de utilizar los mandatos genéricos para el posicionamiento jerárquico y las disputas de autoridad. Adentrarse en esos otros modos implica introducir, aquí, otros escenarios: no ya el conformado por los alumnos del establecimiento, sino por el de sus profesores.

A lo largo de dos años y trece asignaturas ${ }^{20}$ (con dos profesores por cada una de ellas), el desfile de docentes en la Escuela Superior incluyó un espectro tan nutrido como variado: algunos viejos policías retirados, uno que otro policía en ejercicio, un par de funcionarios del Ministerio de Seguridad provincial, muchos abogados y una cantidad modesta de filósofos, psicólogos, historiadores y periodistas. La amplia mayoría se

${ }^{19}$ Que esto haya sido así no significa, en lo absoluto, que esa actuación haya sido una estrategia cuidadosamente planificada. Significa, antes bien, que todos alumnos de la Escuela y joven antropóloga incluida- somos actuados por matrices de género. Significa que las usábamos -en su sentido de echar mano a lo que somos- para construirnos mutuamente

${ }^{20}$ Las asignaturas cursadas en el ámbito de la Escuela eran las siguientes: Derecho Penal, Derecho Procesal Penal, Práctica Procesal, Derecho Administrativo y Legislación Policial, Derecho de Familia y Minoridad, Derecho Constitucional y DDHH, Investigación Criminal, Psicología y Sociología Aplicada, Medicina Legal y Asistencial, Relaciones con la Comunidad, Deontología, Comunicación, y un Ciclo de Conferencias de temas variados. En los centros de reentrenamiento, cercanos a su lugar de destino, los alumnos cumplían, además, con las siguientes asignaturas: Defensa Personal, Entrenamiento Físico, Armamento y Tiro Policial, y Operaciones Policiales. 
avenía de buen grado a mi presencia, sin más consecuencias que la incomodidad normal (y rápidamente superada) de tener un par de ojos tomando nota a su costado. Estaban, por supuesto, aquellos/as con los que hacíamos "buenas migas" y que me incluían activamente en las dinámicas del aula. Había también otros/as con los/as que nos aburríamos mutuamente. Pero había además algunos/as -muy pocos/as- a los que mi asistencia a sus clases incomodaba especialmente.

No la rechazaban directamente, por supuesto (eso hubiera evidenciado grosería tanto como inseguridad), ${ }^{21}$ pero no se privaban de remarcarla, de tanto en tanto, como una entidad intrusiva. "Y ella viene a observar la clase; espero que no al profesor", era el comentario que solía salir a colación en estos casos, hecho éste en un tono liviano y jocoso que no lograba, sin embargo, sonar enteramente despreocupado. En otros, las ocurrencias seguían el mismo parámetro de la gracia, pero sin tanto reparo en sonar conciliadoras: "porque ella tiene el rol de observar y no intervenir, pero supongo que la Licenciada debe poder hilvanar cuatro palabras seguidas". Mi apodo de "la mudita" nació justamente en el seno de las clases de la profesora que oscilaba entre regalarme ese tipo de comentarios y desafiar mi silencio en el aula con pedidos variados de opinión, sólo para subrayar, mirando a todos, cuando yo finalmente contestaba: "¿ven que sí habla?" (eso cuando no se la pasaba haciéndome preguntas que yo, por limitaciones discipinarias, no podía contestar, para entonces retrucarme, con amabilidad almibarada: “pero cómo, Licenciada, ¿no sabe?”).

Los ejemplos podrían seguir, pero sólo para continuar reforzando lo que estos anteriores ya ponen de manifiesto: la incomodidad que mi presencia provocaba en algunos/as profesores/as, y la operación -a medias broma, a medias ofensivaque ponían en marcha para restaurar ese espacio de autoridad supuestamente amenazado.

$21 \mathrm{Y}$, tal vez, en una explicación no menor, problemas con el Director de la Escuela, al estar mi trabajo de campo autorizado directamente por él. 
Pero en este proceso de saldar presencias e incomodidades, los chistes tensos y agresivos no eran los solos mecanismos que se manejaban. No tan curiosamente, los registros de género -ya no los comentarios galantes sino los subidos de tono- se transformaban también en dispositivos idóneos para administrar esa observación que los interpelaba:

Aula 4, clase de Comunicación. La clase entera pasa revista a cómo comportarse cuando toca hablar en público, en conferencias o ruedas de prensa, por ejemplo. El profesor, canchero, da consejos sobre la postura a mantener. Que los brazos atrás parecen de penitente. Que los brazos en jarra de maricones. Que las manos cruzadas adelante dan la idea de que están "cubriéndose los huevos en un tiro libre". Todos se ríen. El del apellido difícil salta, desde el fondo, señalándome con un gesto de la cabeza: "acá la chica no entendió el mensaje". Más risas, a las que me sumo. El profesor dice algo; sólo escucho el final de la frase: "...ella se metió acá, allá ella" (Registro de campo).

El lenguaje escatológico y las alusiones sexuales son chicanas recurrentes en el ámbito policial, de las que todos/as en el campo, yo incluida, nos reíamos. Pero este puñado de declaraciones que nacían como chistes y anécdotas subidas de tono, pronto se transformaban, en mano de estos/as profesores/as, en discursos de producción de la diferencia. Pues no otra cosa hace el profesor del anterior relato, cuando proclama esa suerte de discurso viril y jactancioso ante los alumnos. Porque la exhibición de masculinidad lineal que alumno y profesor despliegan a continuación -que los oídos de las damas no están hechos para "groserías", que escucharlas era mi culpa por haberme metido entre tantos hombres- está hecha para escenificar una identidad masculina centrada en el regodeo del lenguaje "impertinente". Y está hecha, por eso y sobre todo, para convertir ese mandato de habla soez en otro de los registros con que posicionarme genérica y ajenamente. 
Lo que este profesor hacía, en el aula, era ubicarme. En una estructura de género, por supuesto, pero, a través de ella, en una demarcación de jerarquías diferenciales. La construcción de mi feminidad vulnerable a sus discursos "groseros" era un modo de relacionamiento que estaba allí para instaurar la polaridad. El ejercicio de la masculinidad -de esa forma de masculinidad- se volvía así una arena donde sobreimprimir no sólo un amago de orden, sino también una suerte de status: a los ojos de ese profesor, yo no dejaba de caer, siempre, del lado de afuera.

Porque de eso se trata, justamente, el ejercicio del poder jerárquico: de establecer separaciones, de delimitar posiciones y relaciones diferenciales que reproduzcan y mantengan vigente la desigualdad. De establecer contrastes -lo masculino, lo femenino; lo grosero, lo vulnerable; el profesor, la antropóloga-, destacando fronteras sociales y subrayando identidades. El poder se instituye, en tal sentido, como un ejercicio que separa y aísla, que resulta del juego de las diferencias, y que deviene, él mismo, un ejercicio de institución, en tanto sanciona y consagra -a través de sus discursos y exhibiciones- un estado de cosas, un orden establecido que no es otra cosa que un sistema de diferenciación (Balandier, 1994).

La apelación a los chistes "impropios" se volvía así un mecanismo a menudo visitado para el "disciplinamiento" de la antropóloga en el aula. Disciplinamiento no siempre ejecutado a manos de profesores hombres:

Aula 7. La profesora, de impecable uniforme y riguroso rodete (tiene jerarquía de comisario), entrega los exámenes corregidos que tomó la semana anterior. Va y viene entre los bancos, repartiendo calificaciones. El silencio es espeso. Más allá de las chicanas y las risas que suele compartir con los alumnos, éstos saben muy bien, con ella, dónde están los límites. Éste es uno de esos momentos en que sobrevuela, invisible pero palpable, el peso de la jerarquía. Nadie habla mientras ella continúa desfilando entre los bancos. Los que ya tienen sus exámenes, los miran en silencio y los dejan sobre el pupitre, boca abajo. De 
repente, la mirada de la profesora descubre un uniforme sin corbata reglamentaria:

Profesora: ¿Usted es macho, se la banca, que no tiene corbata?

Alumno (dubitativo): No, es que no tengo.

$\mathrm{P}$ : ¿Cómo que no tiene?

A: No, es que no conseguí...

P: ¿Me va a decir que en todos estos años de carrera usted, subinspector, no pudo distraer parte de su sueldo para comprarse una corbata negra? ¿Tengo que entender que en este tiempo no pudo conseguir ninguna? A que si a usted se le acaba la yerba la consigue...Porque si a usted le da calor, a mí también. Y si es por ser macho, yo también soy macho y me la banco.

El silencio, si cabe, se hace todavía más espeso. Nadie habla. Menos que menos el del uniforme sin corbata, que se limita a bajar la vista, deseando que esa asunción de culpa de por concluido el interrogatorio. La profesora se cansa, o encuentra inutil seguir con la reprimenda, o recuerda que todavía, en la mano, tiene exámenes por repartir. Recorre los bancos del fondo, entrega los últimos. Me doy cuenta de que deja el de Leiva para el final. Es el chistoso del curso, pero ahora está callado y tratando de mantener un aire de esforzada seriedad.

P: Tome, Leiva -lo amonesta con sorna y media sonrisa-, tiene un ocho. Y a ver si para la próxima aprende a escribir "apoyo" en vez de "apollo".

La clase, descomprimidos ya los ánimos, estalla en una risa generalizada. Y ella, hábil como nadie para llevarlos del pavor a la carcajada, aprovecha para rematar:

P: Si un varón sano, a su edad, no sabe apoyar...Y esto se lo digo de hombre a hombre, eh -le dice medio inclinándose sobre él-, hagamos de cuenta que no está la Licenciada (Registro de campo).

Es sugerente que, al decir de la profesora, la única presencia que hubiera podido sentirse intimidada por tal lenguaje hubiese sido la mía, en un aula que contaba, además de ella, con otras tres mujeres (alumnas). La inferencia es clara: lejos de no haber lugar 
para la mujer en la dinámica de esa clase, lo que no había era espacio para lo femenino. La afirmación no debiera sorprendernos: en una institución atravesada por fuertes mandatos de masculinidad, ésta se vuelve no sólo un atributo aplicable a la conducta del hombre policía, sino la condición de actuación de todo sujeto policia ${ }^{2}$-comisarios mujeres y alumnas subinspectores incluidas (Sirimarco, 2009).

Ya ha sido suficientemente argumentado que la masculinidad, en tanto modalidad de actuación que presenta ciertas características, bien puede ser ejercida por mujeres (Badinter, 1993; Bonaparte, 1997; Bourdieu, 2000; Burin y Meler, 2000; Halberstam, 2002; Gutmann, 2003; Segato, 2003; Sirimarco, 2009). Así, si los géneros no son más que el registro en el cual nos instalamos al ingresar en una escena, donde masculino y femenino son posiciones relativas, resulta claro comprobar que muchas mujeres policías, socializadas en los valores de la institución, elijan posicionarse en el entramado jerárquico a partir de un discurso y una actitud que incorpora el imperativo de la virilidad -ser activo, prepotente, desafiante- $\mathrm{y}$ remeda el lenguaje masculino. $\mathrm{O}$ a partir de ciertas chanzas consideradas "inadecuadas" para el ámbito de lo femenino.

En todo caso, conviene no perder de vista que la actuación de la profesora del relato anterior no sólo se vuelve un insumo a partir del cual posicionarse jerárquica e imperativamente ante sus alumnos, sino a partir del cual disputar, ante mí, competencias y habilidades. El ejercicio de la masculinidad -entendido aquí como la exhibición de la sexualidad y sus discursos- se transforma así en una herramienta que no sólo le permite desafiarme, a partir de la enunciación de un lenguaje destinado supuestamente a escandalizarme, sino en una herramienta que le permite por ello devolver gentilezas. Esto es, nivelar las incomodidades. En este

\footnotetext{
${ }^{22}$ Hablar de un sujeto masculino no es, evidentemente, hacer referencia a un cuerpo real. La masculinidad debe ser entendida, antes bien, como un cuerpo ideal vehiculizado por representaciones institucionales, donde lo que se pretende es que los policías se piensen según los términos que consiente la estructuración grupal de la realidad (Sirimarco, 2009).
} 
sentido, la resolución de la tensión en base a la performance de género no es sino un modo competente para socavar mi supuesto lugar de autoridad y de marcar, sobre todo, los límites de mi aceptación en el campo (Escolar, 2005).

Se ha dicho largamente que la autoridad etnográfica es una ficción. Los ejemplos mencionados hasta aquí no hacen sino poner esta afirmación en evidencia, ilustrando cómo el status del/a antropólogo/a en el campo -sus posibilidades, sus aciertos, sus limitaciones- es una construcción vincular, donde su aceptación no es una opción más obvia que la de su rechazo (Sirimarco, 2012).

Postular la posibilidad de este último no implica clausurar su explicación aludiendo a la resistencia y opacidad de los sujetos o de las instituciones policiales, ni a una suerte de "maldad" intrínseca de las personas en el campo, encaprichadas en dificultar la tarea del antropólogo. La resistencia con que el/la etnógrafo/a es enfrentado/a se encuentra en el corazón mismo del proceso de investigación y de la producción del conocimiento, allí donde sobrevuela, tácita, una pregunta: ¿qué anotás, de todo lo que ves y lo que pasa? Pero sobre todo, ¿para qué? O dicho de otro modo: ¿quién sos vos para pretender saber?

Conviene tal vez no olvidar, al respecto, que somos, para las personas que conforman nuestro campo, científicos/as avalados/as institucionalmente (universidades, programas, agencias de investigación). Es decir, que encarnamos la autoridad de una ciencia (social) que opera demarcando la existencia de un otro, objetivándolo, recortándolo como universo de análisis y elaborando, finalmente, sobre ese otro, un discurso autorizado que es, a la vez, un espacio de intervención (Tiscornia, 1992; Pita, 1994; Daich y Sirimarco, 2009).

En el despliegue de esta mirada científica -siempre atenta y siempre inquisidora-, las fronteras de género se trazan y se resaltan para servir a una gran variedad de funciones sociales y políticas. $\mathrm{O}$ al menos eso sucedió en mi experiencia de campo, donde las actuaciones genéricas se volvieron, bien pronto, formas mediante las cuales posicionarse frente a la autoridad etnográfica y al proceso de pesquisa. Coqueteándome o exponiéndome a 
"groserías", alumnos y profesores/as encontraban modo de desafiar tanto roles como legitimidades, interviniendo activamente en el transcurso de la investigación. Si no de modo disruptivo, al menos no de modo manso: expresando, merced a esas aproximaciones genéricas, todo lo que la autoridad etnográfica tiene de quebradiza.

El campo, lo sabemos, no es una instancia dúctil a la espera de la observación del/a etnógrafo/a, sino el resultado de encuentros y confrontaciones. Este trabajo ha intentado, justamente, colocar y significar esos enfrentamientos (y sus particularidades) en un contexto epistemológico que permitiera dos movimientos entrelazados. Por un lado, la dislocación de la construcción del sujeto receloso o paranoico con que solemos leer la resistencia de las personas en el campo, articulando la investigación con las relaciones de poder que la subyacen y reposicionando en un plano político la cuestión metodológica de la etnografía y su pretensión de inmersión en la vida de los otros.

Pero también, por otro lado, de matizar con sentidos más complejos el papel de las relaciones de género en el campo. Si ciertos analisis sobre investigadoras mujeres en campos masculinos han tendido a arremolinarse en torno a meditaciones más o menos descriptivas sobre insinuaciones sexuales o avances amorosos, este trabajo ha buscado re-semantizar estas actuaciones genéricas, ubicándolas en una línea de comprensión capaz de iluminar los usos que sobreviven cuando deja de percibirse al género bajo la luz siempre parcial -y un poco sensiblera- de lo amoroso, lo sexual o lo romántico.

En uno y otro caso, de lo que se trató siempre fue de interrogar esos discursos genéricos en tanto productores $y$ vehiculizadores de tensiones profesionales e institucionales. Y de intentar por ende una lectura de tales narrativas en una clave que privilegie -como la teoría feminista se ha encargado de enfatizar- el costado político que tiene toda erótica, donde cuestiones que implican el género y la sexualidad (y sus lenguajes), juegan un rol determinante en la manufactura de nuestros posicionamientos en el campo. 


\section{Referencias bibliográficas}

ALCÁZAR CAMPOS, Ana. 'Siendo una más'. Trabajo de campo e intimidad”. Revista de estudios sociales (49), 2014, pp.59-71.

BADINTER, Elisabeth. XY, la identidad masculina. Bogotá, Editorial Norma, 1993.

BACK, Les. Gendered participation. Masculinity and fieldwork in a south London adolescent community. In: BELL, Diane; CAPLAN, Pat y KARIM, Wazir Jahan (ed.) Gendered fields. Women, men and ethnography. London y New York, Routledge, 1993, pp.215-233.

BALANDIER, Georges. El poder en escenas. De la representación del poder a el poder de la representación. Barcelona, Editorial Paidos, 1994.

BELL, Diane; CAPALN, Pat; KARIM, Wazir Jahan (ed.). Gendered fields. Women, men and ethnography. London y New York, Routledge, 1993.

BONAPARTE, Héctor. Unidos o dominados. Mujeres y varones frente al sistema patriarcal. Rosario Homo Sapiens Ediciones, 1997.

BOURDIEU, Pierre. La dominación masculina. Barcelona, Anagrama, 2000.

BURIN, Mabel; MELLER, Irene. Varones. Género y subjetividad masculina. Buenos Aires, Paidós Editorial, 2000.

BUTLER, Judith. Gender Trouble. Feminism and the subversion of identity. New York, Routledge, 1999.

.El género en disputa. El feminismo y la subversión de la identidad. Barcelona, Editorial Paidós, 2007.

CALANDRÓN, Sabrina. Género y sexualidad en la Policía Bonaerense. San Martín, Unsam Edita, 2014.

CALANDRÓN, Sabrina; GALEANO, Diego. La 'Brigada Femenina': la incorporación de mujeres a la Policía de la Provincia de Buenos Aires (1947-1955). In: SALVATORE, Ricardo; BARRENECHE, Osvaldo (ed.). El delito y el orden en perspectiva histórica. Prohistoria Ediciones, Rosario, 2013, pp.167-186. 
CLIFFORD, James; MARCUS, George (ed.). Writing culture: The Poetics and Politics of Ethnography. Berkeley and Los Angeles, University of California Press, 1986.

CUPPLES, Julie. The filed as a landscape of desire: sex and sexuality in geographical fieldwork. Area (34), 2002, pp.382-390.

DAICH, Deborah; SIRIMARCO; Mariana. Anita anota. El antropólogo en la aldea (penal y burocrática). Cadernos de campo (18), 2009, pp.1328

[http://www.revistas.usp.br/cadernosdecampo/article/view/45433/490 $\underline{42}$ - consultado el 03/03/2018].

. Policías y prostitutas. El control territorial en clave de género. Publicar (XII), 2014, pp.27-45 [http://ppct.caicyt.gov.ar/index.php/publicar/article/view/4702 consultado el 02/05/2018].

DUBISCH, Jill. Lovers in the field. Sex, dominance, and the female anthropologist. In: KULICK, Don; WILLSON, Margaret (ed.). Taboo. Sex, identity and erotic subjectivity in anthropological fieldwork. Routledge, New York, 1995, pp.29-50.

EILBAUM, Lucía; SIRIMARCO, Mariana. Una discusión sobre los procesos de investigación etnográfica en el campo policial y judicial. In: WILDE, Guillermo y SCHAMBER, Pablo (comp.). Culturas, comunidades y procesos urbanos contemporáneos. Editorial SB, Buenos Aires, 2006, pp.103-124.

ESCOLAR, Diego. La soberanía en el campo. Poder, etnografía y secreto en los Andes sanjuaninos. In: WILDE, Guillermo y SCHAMBER, Pablo (comp.). Historia, poder y discursos. Buenos Aires, Paradigma Indicial, 2005, pp.49-76.

FLINN, Juliana. Introduction. The familiy dimension in anthropological fieldwork. In: FLINN, Juliana; MARSHALL, Leslie; ARMSTRONG, Jocelyn (ed.). Fieldwork and families. Constructing new models for ethnographic research. University of Hawai'i Press, British Columbia, 1998, pp.1-21.

FONSECA, Claudia. Família, fofoca e honra. Etnografia de relações de gênero e violência em grupos populares. Porto Alegre, Universidade/UFRGS, 2000. 
GILL, Fiona; MACLEAN, Catherine. Knowing your place: gender and reflexivity in two ethnographies. Sociological research online (7), $2002, \mathrm{~s} / \mathrm{d}$.

GOLDE, Peggy. Women in the field. Anthropological experiences. California, University of California Press, 1986.

GUTMANN, Matthew. Changing men and masculinities en Latin America. Durham y Londres, Duke University Press, 2003.

HALBERSTAM, Judith. An introduction to female masculinity: masculinity without men. In: ADAMS y SAVRAN (comp.). The masculinity studies reader, Blackwell Publishers, Oxford, 2002, pp.143.

HUGGINS, Martha; GLEBBEEK, Marie Luise. Women studying violent male institutions: crossed gender dynamics in police research on secrecy and danger. Theoretical Criminology (7), 2003, pp.363-387.

KULICK, Don; WILLSON, Margaret (ed.). Taboo. Sex, identity and erotic subjectivity in anthropological fieldwork. New York, Routledge, 1995.

LAMAS, Marta. Género, diferencias de sexo y diferencia sexual. In: A. RUIZ (comp.). Identidad femenina y discurso jurídico. Editorial Biblos, Buenos Aires, 2000, pp.65-84.

LANGARITA ADIEGO, José Antonio. On sex in fieldwork: notes on the methodology involved in the ethnographic study of anonymous sex. Sexualities (0), 2017, pp.1-15.

MARCUS, George; FISHER, Michael. Anthropology as Cultural Critique: An Experimental Moment in the Human Sciences. Chicago and London, University of Chicago Press, 1986.

MARKOWITZ, Fran. Sexualizando al antropólogo: implicaciones para la etnografía. In: NIETO, José Antonio (ed.). Antropología de la sexualidad y diversidad cultural. Talasa Ediciones, Madrid, 2003, pp.79-92.

MOREIRA, María Verónica. Una mujer en campo masculino y la identificación de género en el proceso de producción del conocimiento antropológico. Ponencia en IV Jornadas sobre Etnografía y Métodos Cualitativos, Buenos Aires, 2004 [http://www.wwc2017.eventos.dype.com.br/fg7/artigos/M/Maria Vero nica_Moreira_33.pdf -consultado el 22/11/2017]. 
PISCITELLI, Adriana. Ambigüedades y desacuerdos: los conceptos de sexo y género en la antropología feminista. Cuadernos del INAPL (16), 1995 ,

pp.153-170 [https://revistas.inapl.gob.ar/index.php/cuadernos/article/view/475 consultado el 09/04/2018].

PITA, María Victoria. Horizontes artificiales. Acerca de la posibilidad de una lectura crítica desde la antropología política. Ponencia en $I V$ Congreso Argentino de Antropología Social, Universidad Nacional del Centro, Facultad de Ciencias Sociales e Instituto de Investigaciones Antropológicas, Olavarría, 1994. Mimeo.

RODRIGUEZ, Adolfo; ZAPPIETRO, Eugenio. Historia de la Policía Federal Argentina. A las puertas del tercer milenio. Buenos Aires, Editorial Policial, 1999.

SCOTT, Joan. El género: una categoría útil para el análisis histórico. In: LAMAS, Marta (comp.). El género: la construcción cultural de la diferencia sexual. PUEG, México, 1996, pp.265-302.

. Unanswered questions. American Historical Review, vol.113, 2008, pp.1422-1430.

SEGATO, Rita. Las estructuras elementales de la violencia. Bernal, Universidad Nacional de Quilmes, 2003.

SIRIMARCO, Mariana. De civil a policía. Una etnografía del proceso de incorporación a la institución policial. Buenos Aires, Editorial Teseo, 2009.

. Historias de cercanías, de distancias, de una ida y un regreso. El periplo del trabajo de campo en una escuela de policía. In: SIRIMARCO, Mariana (comp.). Estudiar la policía. La mirada de las ciencias sociales sobre la institución policial. Buenos Aires, Editorial Teseo, 2010, pp.301-322.

- El policía y el etnógrafo (sospechado). Disputas de roles y competencias en un campo en colaboración. Etnografica (vol.16), 2012 , pp.269-290 [http://www.scielo.mec.pt/scielo.php?script $=$ sci abstract\&pid $=$ S087365612012000200003\&lng=pt\&nrm=iso - consultado el 24/05/2018]. 
. La construcción de lo indecible: chisme, dato y etnografía en un contexto policial argentino. Revista de Antropología Social vol.26, 2017, [https://www.redalyc.org/articulo.oa?id=83851421003 - consultado el 26/05/2018].

STOLCKE, Verena. La mujer es puro cuento: la cultura del género. Estudos Feministas (12), 2004, pp.77-105 [https://www.scielo.br/pdf/ref/v12n2/23961.pdf - consultado el 13/06/2018].

STRATHERN, Marilyn. The gender of the gift. California, University of California Press, 1988.

TISCORNIA, Sofía. Antropología política y criminología. Acerca de la construcción de dominios en el control de la 'otredad'. Publicar. Antropología y Ciencias Sociales (1), 1992, pp.53-68.

WILLIAMS, Brackette. Skinfolk, not skinfolk: comparative reflections on the identity of participant-observation in two field situations. In: WOLF, Diane (ed.). Feminist dilemmas in fieldwork. Westview Press, Colorado, 1996, pp.72-95.

WOLF, Diane. Situating feminist dilemmas in filedwork. In: WOLF, Diane (ed.). Feminist dilemmas in fieldwork. Westview Press, Colorado, 1996, pp.1-55. 